\title{
HER2 EXPRESSION IN RENAL CELL CARCINOMA
}

\author{
S. Spasova*, N. Petrova, P. Ghenev \\ Department of General and Clinical Pathology, Forensic Sience and Deontology, Medical University, \\ Varna, Bulgaria
}

\begin{abstract}
Renal cell carcinoma (RCC) is the most common malignancy of the adult kidney. A variety of proteins have been investigated for their use as prognostic tumor markers. At present, there are conflicting reports concerning HER2 expression in RCC.

PURPOSE: The aim of this study is to evaluate the expression of HER2 protein in patients with renal cell carcinoma (RCC) and to determine the relationship between the tumor grading, staging and the type of the tumor.

METHODS: The expression of HER2 in renal cell carcinoma was studied using immunohistochemical methods in paraffin-embedded specimens from 34 patients. Of these cases, 19 patients had clear cell carcinoma, 6 had chromophobe, 5 had papillary, and 4 had urothelial renal carcinoma. Nine of the patients had metastases (in regional lymph nodes and distants), 25 patients were without metastases. The membranous staining of HER2 was assessed as positive when the score was higher than $2(0,1-$ negative, 2, 3 - positive), according to the well accepted scoring system for breast cancer.

RESULTS: The results showed that there were varying degrees of HER2 expression in different RCC's histological types. The same changes in HER2 expression can be seen in the tumors with and without metastases. There was no significant association between HER2 overexpression and tumor stage, grade and the type of tumor. The results of the present study point out the necessity to discuss eventual beneficial effect of Herceptin therapy.
\end{abstract}

Key words: renal cell carcinoma, HER2, immunohistochemistry

\section{INTRODUCTION}

Renal cell carcinoma (RCC) is the most common malignant tumor of the human urinary system. The classic presentation of RCC includes the triad of flank pain, hematuria, and a palpable abdominal mass. Few patients now present in this way and roughly half of the cases are detected as a renal mass, incidentally identified on radiographic examination. Risk factors for RCC include smoking, obesity, and hypertension, as well as acquired cystic kidney disease associated with end-stage renal failure. The World Health Organization classification divides RCC into clear cell, chromophobe, papillary, collecting duct, and other rare subtypes. As conventional prognostic markers the TNM staging system [1], Fuhrman nuclear grade [2], tumor necrosis [3], and vascular invasion [4] are used. Currently, the main

\footnotetext{
*Correspondence to: S. Spasova, Department of General and Clinical Pathology, Forensic Sience and Deontology, Medical University - Varna, Bulgaria, phone 052/978 520, e-mail: dr.spasova@gmail.com
}

treatment includes surgical removal, radiology and chemotherapy but they still have unsatisfactory success. Immunotherapy with IFN and IL2 is also used [5]. Therefore identification of new molecules and signaling pathways is needed for more effective targeted therapy. In this regard, an eventual candidate could be HER2. The HER2 (c-erbB2) gene, a proto-oncogene, encodes epidermal growth factor receptor HER2, a transmembrane glycoprotein receptor $\mathrm{p} 185^{\mathrm{HER} 2}$, which is targeted by the humanized monoclonal antibody trastuzumab (Herceptin)[6]. HER2 combines with the other EGFRs is involved in signal transduction, cell proliferation, development, differentiation, migration and tumor formation. All this events are entirely valid for RCC. At present, there are some conflicting reports concerning HER2 expression in RCC. The aim of this study is to comprehensively investigate the frequency of HER 2 overexpression in RCC and to search for any relationship with other factors as gender, age, lymph node metastasis and tumor stage. 


\section{MATERIALS AND METHODS}

The study is based on 34 cases of surgically removed RCC, including 25 males and 9 females; age ranging from 41 to 82 years with a mean of 62 years. Histologic type of each tumor was defined according to WHO classification, 2004. The histologic staging and grading were done according to the UICC TNM classification. Biopsy tissue samples were formalin fixed and paraffin embedded, processed routinely for light microscopy observations. Immunohistochemical analysis was performed using anti HER2-2/neuspecific polyclonal antibody, Code A0485 from DAKO, according to the manufacturer guidelines. The expression of HER2 was evaluated by two pathologists. The intensity of HER2 staining was graded as $0,1+, 2+$, or $3+$. According to the new ASCO/CAP guidelines score 0 was given for no staining or staining in fewer than $10 \%$ of the tumor cells, $1+$ for weak and incomplete membrane staining in more than $10 \%$ of the tumor cells, $2+$ for tumors with weak to moderate complete membrane staining in more than $10 \%$ of the cells, and $3+$ for strong and complete membrane staining in more than $30 \%$ [7]. The membranous staining of HER 2 was assessed as positive when the score was higher than $2(0,1$-negative, 2, 3 - positive), according to the well accepted scoring system for breast cancer.

Chi-square test was used to analyze the relationship between the expression of HER 2 and other clinicopathologic parameters (such as age, gender, histological type of the tumor stage and presence of metastasis).

\section{RESULTS}

Out of all 34 cases, 19 had clear cell, 6 chromophobe, 5 - papillary, and 4 - urothelial renal carcinoma. At the time of diagnosis, 9 of the patients had metastases in regional lymph nodes and distant sites and 25 patients were without metastases. The exact distribution of these parameters in regard to HER2 expression is presented on Table 1.

Table 1. Clinicopathologic Parameters of Patients With RCC - with and without metastasis

\begin{tabular}{|r|c|c|}
\hline & $\begin{array}{l}\text { With } \\
\text { metastases } \\
9\end{array}$ & $\begin{array}{c}\text { Without } \\
\text { metastases } \\
25\end{array}$ \\
\hline Age & & \\
\hline$<65$ & $5(55.55 \%)$ & $18(72 \%)$ \\
\hline$>65$ & $4(44.44 \%)$ & $7(28.00)$ \\
\hline Sex & & \\
\hline Female & $2(22.22 \%)$ & $7(28.00 \%)$ \\
\hline Male & $7(77,77 \%)$ & $18(72 \%)$ \\
\hline HER2 & & $p=0,493$ \\
\hline 0 & - & $2(8 \%)$ \\
\hline 1 & $4(44.44 \%)$ & $6(24 \%)$ \\
\hline 2 & $5(55.55 \%)$ & $15(60 \%)$ \\
\hline 3 & - & $2(8 \%)$ \\
\hline
\end{tabular}

Of a total of 34 tumor HER2 positive membranous staining (higher than 2) was observed in $22(64,71 \%)$, only two of them with a value above $3+$ (strongly positive). Negative expression $(0$ and $1+)$ was observed in $12(35,29 \%)$. The results showed that there were varying degrees of HER2 expression in different RCC's histological types. RCC parameters in regard to HER2 expression are demonstrated on Table 2.

Table 2. Associations of HER2 expression with Pathological Features in RCC

\begin{tabular}{|c|c|c|c|c|}
\hline HER2 & 0 & $1+$ & $2+$ & $3+$ \\
\hline $\begin{array}{ll}\text { Primary } & \text { tumor } \\
\text { size } & \\
& <5 \mathrm{~cm}\end{array}$ & 1 & 2 & & $p=0,149$ \\
\hline $5-7$ & & 4 & 7 & 1 \\
\hline $8-10$ & & 3 & 10 & \\
\hline$>10$ & 1 & 1 & 3 & 1 \\
\hline T stage & & & & \\
\hline pT1-2 & - & 6 & 12 & 1 \\
\hline pT3-4 & 2 & 4 & 8 & 1 \\
\hline Tumor type & & & & $p=0,372$ \\
\hline Clear cell & & 7 & 10 & 2 \\
\hline Chromophoe & & 2 & 4 & \\
\hline Papillary & 1 & & 4 & \\
\hline Urothelial & 1 & 1 & 2 & \\
\hline $\begin{array}{l}\text { Regional } \\
\text { lymph node } \\
\text { involvement }\end{array}$ & & & & $p=0,507$ \\
\hline $\mathrm{pNx} p \mathrm{pN}$ & 2 & 6 & 15 & 2 \\
\hline pN1 pN2 orM1 & & 4 & 5 & \\
\hline
\end{tabular}

The HER2 positive reaction does not correlate with tumor type, primary tumor size and $\mathrm{T}$ stage.

\section{DISCUSSION}

In recent years the importance of tumor biology has become increasingly important for the development, treatment and prognosis of cancers. HER2 gene amplification and protein overexpression are thought to be important oncogenic transformation and tumorigenesis and is associated with a poor prognosis in variety of carcinomas. Our results show high HER2 positive expression - $64,71 \%$ of all RCC cases, while overexpression of the HER2/neu oncogene is observed just in approximately $30 \%$ of human breast carcinoma specimens [8]. HER2/neu overexpression is a negative prognostic factor in breast cancer patients [9]. Validated methods and scoring systems for evaluating HER2 status exist in breast cancer, but the prognostic/predictive value for carcinoma of the kidney is unclear, although the incidence of HER2 positivity is 
SPASOVA S., et al.

considerably higher. Other authors also reported a positive expression of HER2 in RCC in $40 \%$ using IHC and suggest that the abnormalities of HER2 may be involved in the pathogenesis of RCC [10]. The same high incidence is established in a similar study (Stumm et al). They also examined $34 \mathrm{RCC}$ for amplification and expression of the HER-2/neu gene. In addition, they have also found statistically significant association with higher tumor grades and metastatic disease. Our results failed to confirm this association, but we did not perform in situ hybridization. Analyzing the co-overexpression of both receptor types - EGF receptor and p185erbB2 their results suggest a synergistic involvement of both in the progression of RCC [11]. Application of HER2 approach seems to be even more important since HER2 positivity is established in other tumor locations too - in non-small-cell lung cancer [12], ovarian [13], stomach [14, 15], and aggressive forms of uterine cancer, such as uterine serous endometrial carcinoma [16]. Other opinions consider HER2 as not important in the tumor progression of RCC $[17,18]$, but these results are not supported by newer findings. In conclusion, we think we have enough preliminary evidence to suggest HER2/Herceptin approach worth for discussion in RCC.

\section{REFERENCES}

1. Yasunaga, Y., et al., [Validation of 2009 TNM classification based on a prognostic analysis of 350 patients treated for renal cell carcinoma]. Nihon Hinyokika Gakkai Zasshi, 2012. 103(3): p. 540-7.

2. Fuhrman, S.A., L.C. Lasky, and C. Limas, Prognostic significance of morphologic parameters in renal cell carcinoma. Am J Surg Pathol, 1982. 6(7): p. 655-63.

3. Martin Pichler, M., Georg C. Hutterer, MD, Thomas F. Chromecki, MD, Johanna Jesche, MD, and M. Karin Kampel-Kettner, Peter Rehak, PhD, Karl Pummer, MD, and Richard Zigeuner, MD, Histologic Tumor Necrosis Is an Independent Prognostic Indicator for Clear Cell and Papillary Renal Cell Carcinoma. Am J Clin Pathol, 2012. 137: p. 283-289.

4. Pichler, M., et al., Prognostic value of the Leibovich prognosis score supplemented by vascular invasion for clear cell renal cell carcinoma. J Urol, 2012. 187(3): p. 834-9.

5. Fossa, S.D., Interferon in metastatic renal cell carcinoma. Semin Oncol, 2000. 27(2): p. 187-93.

6. Baselga, J., et al., Phase II study of weekly intravenous recombinant humanized anti-
p185HER 2 monoclonal antibody in patients with HER2/neu-overexpressing metastatic breast cancer. J Clin Oncol, 1996. 14(3): p. 737-44.

7. Yan-Hui Liu, F.-P.X., Jian-Yu Rao, HengGuo Zhuang, and L.L. Xin-Lan Luo, MS, Dong-Lan Luo, MS, Fen Zhang,and Jie Xu, Justification of the Change From $10 \%$ to $30 \%$ for the Immunohistochemical HER 2 Scoring Criterion in Breast Cancer. Am J Clin Pathol 2009. 132: p. 74-79.

8. Dowsett, M., et al., Assessment of HER2 status in breast cancer: why, when and how? Eur J Cancer, 2000. 36(2): p. 170-6.

9. Roh, H., et al., HER2/neu antisense targeting of human breast carcinoma. Oncogene, 2000. 19(53): p. 6138-43.

10.Xiang-Hua Zhang, I.T., Chubun Sato, Haruhiko Sakamoto, P53 and her-2 alterations in renal cell carcinoma. Urology, 1997. 50: p. 636-42.

11.Stumm, G., et al., Concomitant overexpression of the EGFR and erbB-2 genes in renal cell carcinoma (RCC) is correlated with dedifferentiation and metastasis. Int J Cancer, 1996. 69(1): p. 1722.

12.F R Hirsch1, M.V.-G.a.F.C., Predictive value of EGFR and HER2 overexpression in advanced non-small-cell lung cancer. Oncogene, 2009. 28: p. 32-37.

13.Han, C.P., et al., HER2 gene amplification in primary mucinous ovarian cancer: a potential therapeutic target. Histopathology, 2010. 57(5): p. 763-4.

14.DM, D.E.C., et al., Immunohistochemical expression of her2 in adenocarcinoma of the stomach. Arq Gastroenterol, 2015. 52(2): p. 152-5.

15.Bartley, A.N., et al., Template for Reporting Results of HER2 (ERBB2) Biomarker Testing of Specimens From Patients With Adenocarcinoma of the Stomach or Esophagogastric Junction. Arch Pathol Lab Med, 2015. 139(5): p. 618-20.

16.Alessandro D. Santincorrespondenceemail, S.B., Juan J. Roman, Jesse K. McKenney, Sergio Pecorelli, Trastuzumab treatment in patients with advanced or recurrent endometrial carcinoma overexpressing HER2/neu. Int J Gynaecol Obstet 2008. 102(2): p. 128-131.

17.Rotter, M., et al., Expression of HER-2/neu in renal-cell carcinoma. Correlation with histologic subtypes and differentiation. Int $\mathrm{J}$ Cancer, 1992. 52(2): p. 213-7.

18.Latif, Z., et al., Gene amplification and overexpression of HER2 in renal cell carcinoma. BJU Int, 2002. 89(1): p. 5-9. 
SPASOVA S., et al. 